\title{
Surface Modification of Forming Tools for Aluminum Sheet Metal Forming
}

\author{
Florian Kuisat ${ }^{1}$, Tim Abraham² ${ }^{2}$, Torsten Schmidt ${ }^{3}$, Martin Weber $^{2}$, Matthias Demmler ${ }^{3}$, Günter Bräuer ${ }^{2}$, \\ Andrés Fabián Lasagni ${ }^{1}$ \\ ${ }^{1}$ Institut für Fertigungstechnik, Technische Universität Dresden, George-Baehr-Str. 3c, \\ 01069 Dresden, Germany \\ E-mail: florian.kuisat@tu-dresden.de \\ ${ }^{2}$ Fraunhofer-Institut für Schicht- und Oberflächentechnik IST, Bienroder Weg 54E, \\ 38108 Braunschweig Germany \\ ${ }^{3}$ Fraunhofer-Institut für Werkzeugmaschinen und Umformtechnik IWU, Reichenhainer Straße 88 \\ 09126 Chemnitz Germany
}

It is known that surface patterns and coating systems can affect the flow behavior of forming tools. In this context, we report about the surface modification of forming tool steels for aluminum sheet metal forming process. Microstructures with variable spatial periods and depths are fabricated on tool steel samples using the direct laser interference patterning method. A picosecond-pulsed infrared laser source with a two-beam interference setup is applied for producing line-like structures. In addition, a diamond like carbon (DLC) coating system is deposited on the structured surfaces. To improve the adhesion tendency of the DLC coating, also different plasma nitriding parameters are examined. According to the results, a broad spectrum of different coating-structure combinations can be efficiently processed, which can optimize the tribological properties of the forming tool for aluminum forming applications.

DOI: $10.2961 /$ jlmn.2020.01.2009

Keywords: direct laser interference patterning, micro-structuring, coating systems, nitriding processes, tool steel

\section{Introduction}

Due to its low weight and excellent energy absorption capacity, aluminum is an excellent material for a wide range of applications, such as in the automotive or aerospace industry. However, the design of forming technologies for aluminum alloys still presents some challenges. For instance, the strong adhesion tendency of these materials leads to high adhesive wear on forming tools [1] and affects the surface quality of components, the process stability and the targeted tolerances. Thus, a high amount of lubricant is currently used to reduce the adhesive tool wear and to enable the production of aluminum alloy components [1]. In order to improve the ecological and economical effectiveness of current production processes, effective strategies have to be developed to reduce the amount of lubricants without increasing the wear tendency.

It is well known, that the properties and functions of a surface can be controlled by specific adaptation of the surface conditions such as using microstructures or coating systems. To control the surface topography of materials, Direct laser writing (DLW) and direct laser interference patterning (DLIP) are effective methods for the production of structures in a wide range of applications for several materials. In particular, several applications where these technologies have been applied were inspired by nature [25]. DLW and DLIP enable the production of microstructures with different achievable structure sizes. For example, the feature size of the DLW is typically in the range of $10 \mu \mathrm{m}$ to $250 \mu \mathrm{m}$ and is limited by the diameter of the focused laser beam. If ultra-short laser pulses are used, struc- tures with smaller feature sizes can be also obtained within the laser spot such as Laser Induced Periodic Surface Structures (LIPSS) [6].

The production of structures with significantly higher resolutions compared to DLW are possible by using the DLIP-technique. This method allows structure sizes up to half of the used laser wavelength. In case of a two laser beam configuration, their characteristic repetitive distance (spatial period) can be calculated using equation 1 [7]:

$$
\Lambda=\lambda /(2 \cdot \sin (\theta / 2))
$$

As it can be observed, the spatial period $(\Lambda)$ is a function of the laser wavelength $(\lambda)$ and the half intersection angle $(\theta)$ between the laser beams.

In the past, several research works have been performed for structuring different materials using this method. For instance, Aguilar-Morales et al. created periodic microstructures with spatial periods ranging from $2.6 \mu \mathrm{m}$ to $5.2 \mu \mathrm{m}$ using picosecond laser system emitting $1064 \mathrm{~nm}$ wavelength [8] in steels. Depending on the number of beams, the structure geometry can be changed as has been shown by Indrisiunas et al. For instance, a two-beam interference setup generates a line-like intensity profile [9], while a four-beam interference setup generates a dot-like geometry [10]. Recently, different DLIP optics have been developed for high-throughput processing. For instance, Lang et al. developed a two-beam DLIP system using a rectangular elongated laser spot at the substrate reaching processing speeds up to $\sim 0.9 \mathrm{~m}^{2} / \mathrm{min}$ [11]. Overall, DLIP has become one of the most efficient techniques for struc- 
turing materials with high quality, throughput and flexibility [12]. Regarding the tribological performance of surfaces, Rosenkranz et al. demonstrated how to reduce the coefficient of friction of DLIP treated metals by controlling the interface contact area [9].

Similar to the micro structuring process, the surface properties can be also modified by the deposition of hard thin film coatings. Within a wide range of different coating classes, amorphous hydrogenated carbon coatings (a-C:H) are well known for their exceptional tribological properties [13-15]. These materials exhibit both low friction and high wear resistance and are already in use in several forming applications. Numerous investigations reported a low adhesion tendency in contact with aluminum [16-18] which will be attributed to the intrinsic capability of self-lubrication and a high inertness of the passivated surface $[17,18]$.

A critical property of a-C:H coatings for its usage in forming processes is the adhesive strength to the tool surface. To improve the adhesive strength, a-C:H coatings are commonly deposited as coatings systems with metallic adhesion and intermediary [21]. As an alternative or addition, the steel tools can be plasma nitrided prior to the deposition of the a-C:H coating system leading to a significant increase in the load resistance of a-C:H coatings [22], also known as duplex process.

This study concentrates on the combination of established surface treatment methods based on laser radiation and surface coating in order to improve the tribological performance of forming tools. For this reason different procedures are developed for improving the performance of forming processes combining DLIP-surface structuring with the deposition of a-C:H coating systems on a hot work steel. An important aspect of the investigation is to determine the achievable structure resolution, which is a relevant property for adjusting the hydrodynamic effectiveness of lubricants in forming processes. Additionally, plasma nitriding of the tool steel is used prior the deposition and structuring of the forming tools to evaluate the impact on the adhesive strength of the a-C:H coating to the structured surface, which is a critical for the usage in forming applications.

\section{Experimental procedure}

The experiments were performed on discs made of the hot work steel 1.2343 with a diameter of $35 \mathrm{~mm}$ and a thickness of $4 \mathrm{~mm}$. This material is characterized by high strength and ductility and is frequently used for forming tools [23]. The discs were electro-polished prior to the plasma nitriding and DLIP-structuring process using a $3 \mu \mathrm{m}$ diamond suspension and subsequently cleaned with isopropanol and ethanol. For the surface modification, the following two treatment sequences were exerted:

(i) Surface polishing; DLIP-structuring; coating deposition

(ii) Surface polishing; plasma nitring; polishing; DLIPstructuring; coating deposition

\subsection{Plasma nitrating and a-C:H deposition}

Main goal of the nitriding process was the optimization of the adhesion tendency of the DLC coating system by lowering the hardness gradient in the surface boundary [24]. For the plasma nitriding process, an industrial plasma diffusion chamber with unipolar pulse plasma supply was used. Here, two complementary nitriding parameter sets were defined to evaluate the impact of the plasma nitriding on the adhesion tendency. Nitrogen flow (10\% and $80 \%$ of total flow), nitriding time $(8 \mathrm{~h})$, pressure $(350 \mathrm{~Pa})$ and substrate temperature $\left(520^{\circ} \mathrm{C}\right)$ were adjusted according to prior investigations [25].

The a-C:H coating system was deposited by a plasma assisted chemical vapour deposition process (PACVD) with acetylene $\left(\mathrm{C}_{2} \mathrm{H}_{2}\right)$ as the precursors gas combined with argon as process gas. To enhance the coating adhesion, the substrates were sputtered clean for $30 \mathrm{~min}$ at the beginning of the coating process and an interlayer based on titanium with a thickness of $0.2 \mu \mathrm{m}$ was applied by magnetron sputtering. The thickness of the complete a-C:H coating system was $2.2 \mu \mathrm{m}$. A more detailed description of the deposition process and the coating characteristics is stated in [26].

\subsection{Direct Laser Interference Patterning treatment}

The laser experiments were realized using the direct laser interference patterning (DLIP) technology. The used setup is illustrated in Fig.1. To produce the line-like patterns, two round shaped Gaussian laser beams were overlapped on the substrate at a certain angle. At this region, a periodic intensity profile is produced which can be directly transferred to the materials surface by selective melting or ablation at the interference maxima positions [27-29].
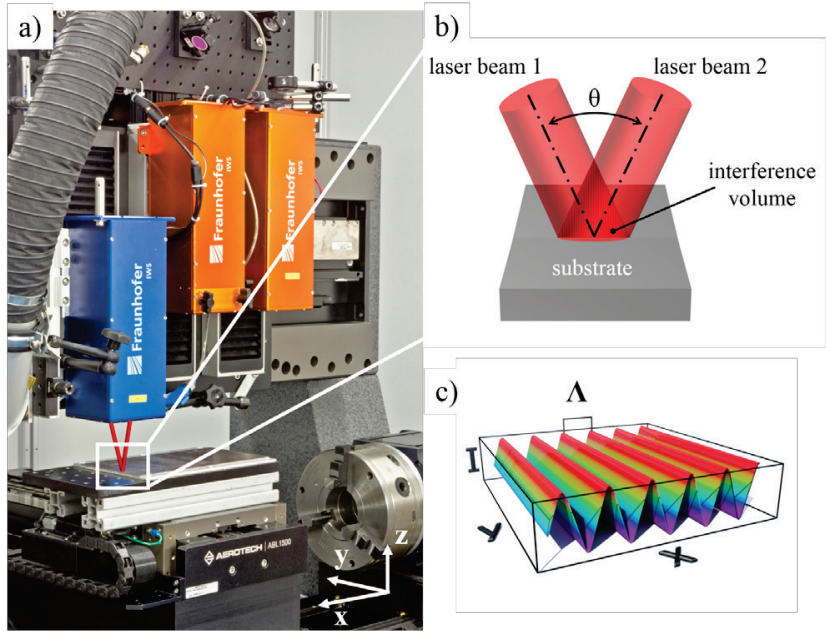

Fig. 1 (a) DLIP workstation developed at TU Dresden for processing of 2D- and 3D-parts; (b) Representation of two overlapped laser beams with the intersection angle and the interference area; (c) intensity profile within the interference volume and the spatial period $(\Lambda)$ between two intensity maxima.

The DLIP workstation uses a solid-state laser system (Edgewave PX2000) which emits light with a wavelength of $1064 \mathrm{~nm}$. The pulse duration was $10 \mathrm{ps}$ pulses and the repetition rate can be changed up to $10 \mathrm{kHz}$. The diameter of the interference area is approximately $196 \mu \mathrm{m}$. In the DLIP optical head, the incident beam is divided by a diffractive optical element into two beams of comparable intensities. Then, the beams are parallelized using a prism and finally overlapped with a converging lens on the substrate. The angle of incidence defines the spatial period. Spatial periods of $3.0 \mu \mathrm{m}$ and $6.0 \mu \mathrm{m}$ were produced by setting the angle $\theta$ to $20.4^{\circ}$ and $10.2^{\circ}$, respectively (see Eq. 1). Further information about the experimental setup has 
already been published elsewhere [30]. By moving the samples in $\mathrm{x}$ - and $\mathrm{y}$ - directions, using an Aerotech axis system, larger areas can be processed (up to $300 \mathrm{~mm} \mathrm{x}$ $600 \mathrm{~mm}$ ). Variation of the hatch distance in $\mathrm{x}$-direction and pulse to pulse distance in y-direction (overlap) determined the homogeneity and structure depth. Fig. 2 shows schematically the process strategy utilized in this work, following the strategy developed in Aguilar-Morales [30]. By setting the pulse overlap and thus the number of pulses per area it is possible to control the energy introduced into the material. In particular, this strategy has shown to be very efficient for adjusting the structure depth. In the experiments, the hatch distance was set to $60 \mu \mathrm{m}$ and the overlap was varied from $80 \%$ up to $97.5 \%$ to achieve the required structure depths according to Rosenkranz [9]. Pulse overlaps below $80 \%$ led to structure depths of approx. $0.2 \mu \mathrm{m}$ and were found out in preliminary investigations.

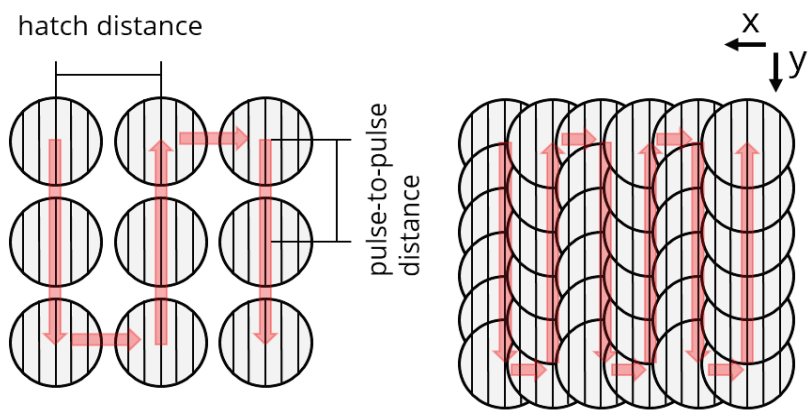

Fig. 2 Schematic drawing of the moving process strategy with and without pulse overlap in $\mathrm{x}$ - and $\mathrm{y}$-direction for the DLIP process.

\subsection{Tribological investigations}

Various tribological test methods, such as the strip tensile test, are known in forming technology. However, for an effective characterization of the tribological properties in this study a new screening test was developed for the microstructured test specimens. W. Rehbein's investigations served as the basis of the new test method [31]. For the investigations a translatory tribometer (SRV5 Optimol) was applied with a pin on disc specimen configuration, like shown in Fig. 3.

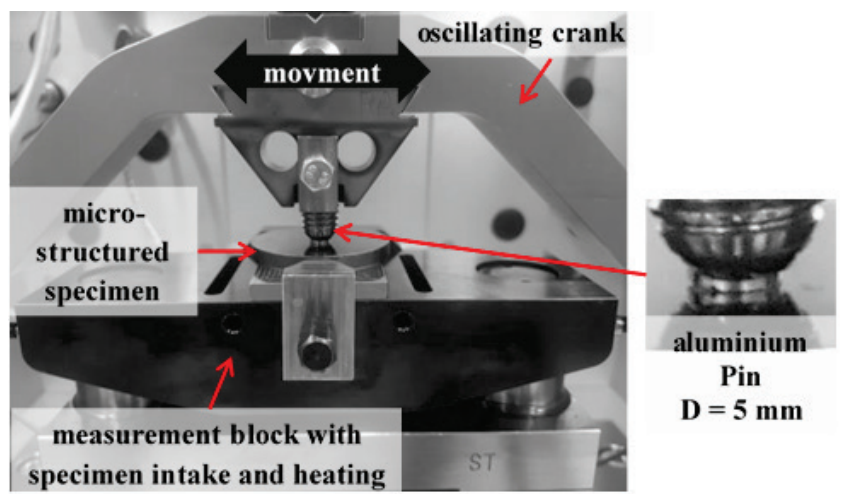

Fig. 3 tribological test assembly (SRV5 Optimol).

The test scenario envisages an increasing load in six stages from $6 \mathrm{MPa}, 16 \mathrm{MPa}, 30 \mathrm{MPa}, 50 \mathrm{MPa}, 76 \mathrm{MPa}$ to $100 \mathrm{MPa}$, with $4 \mathrm{~mm}$ stroke and lubrication with KTL N20. The range of the selected pressure values was derived from the critical strain of geometry changes in the sheet metal forming process. In order to obtain a larger number of measurement results in the lower pressure range, the pressure levels for experimental testing were selected at a nonuniform distance. The test conditions in the higher pressure range were technically limited to $100 \mathrm{MPa}$.

In addition, the specimen temperature was set at $100^{\circ} \mathrm{C}$ The load levels were chosen with regard to different loads in the forming process. The test frequency was set at $4.2 \mathrm{~Hz}$ and corresponds to a speed of approx. $2 \mathrm{~m} / \mathrm{min}$, which is also comparable for forming processes.

The mean coefficient of friction per load level and the accumulated deviation of the stroke movement per load level were used to evaluate the results. The characterization and evaluation of structured and unstructured test specimens were based on the selected assessment criteria.

\subsection{Surface and material characterization}

For the analysis of the surface morphology of the produced textures, White Light Interferometer (WLI, Sensofar S Neox) with 50x magnification was used. Also, Scanning Electron Microscopy (SEM, XL30 ESEM-FEG) as well as an energy-dispersive X-Ray spectroscopy (EDX) were used to analyze the surface topology as well as the chemical distribution of elements.

The hardness depth profiles of the plasma nitrided samples and the coating hardness were determined with a commercial hardness tester (Fischerscope H 100) recording load versus depth curves up to $30 \mathrm{mN}$ (coating) and $50 \mathrm{mN}$ (nitride steel). The hardness of the a-C:H coating measured $34.1 \mathrm{GPa}$. The abrasive wear rate of $1.010^{-15} \mathrm{~m}^{3} / \mathrm{Nm}$ was determined with the ball cratering test [32] operating with an alumina $\left(\mathrm{Al}_{2} \mathrm{O}_{3}\right)$ suspension (mean alumina grain size $1 \mu \mathrm{m})$. Roughness data were collected using an Atomic Force Microscope (Bruker Veeco Dimension 3100) in tapping mode measuring an arithmetical mean height of $10 \pm$ $2 \mathrm{~nm}$ for the polished disc and $15 \pm 1 \mathrm{~nm}$ for the unstructured a-C:H coating. To evaluate the adhesive strength of the a-C:H coating to the structured surface Rockwell tests were conducted according to ISO 26443.

\section{Results and discussion}

\subsection{Properties of plasma nitrided hot work steel}

The adhesive strength of the tool coating to the tool surface is a critical property for the lifetime of coated forming tools. To evaluate the need of a prior plasma nitridring of the hot work steel, additional samples were plasma nitrided based on two different parameter sets and compared with untreated steel samples.

The hardness depth profiles of the nitrided hot work steels are summarized in Fig. 4, presenting an increased hardness near the surface. Depending on the total used Nitrogen flow, the maximum hardness and depth varied. Using a gas flow of $10 \% \mathrm{~N}_{2}$ (dashed black line) a maximum hardness of $1185 \mathrm{HV}$ pl was obtained dropping on the typical hardness level of the hot work steel within a depth of $60 \mu \mathrm{m}$. With a higher gas flow of $80 \%$ (continuous black line), the maximum hardness increased up to $1430 \mathrm{HVpl}$ with a nitriding depth of $160 \mu \mathrm{m}$. 


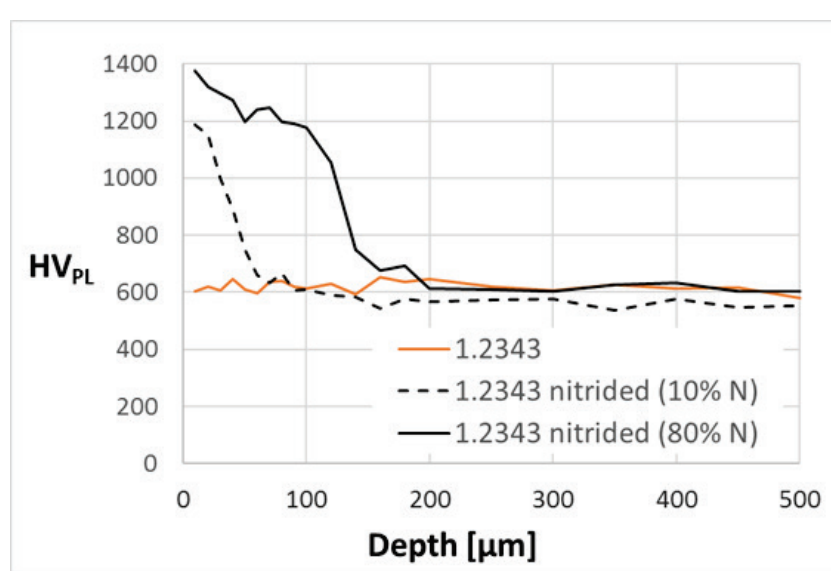

Fig. 4 Hardness depth profiles of the hot work steel 1.2343 in the untreated (orange) and plasma nitrided (black) conditions under variation of the total nitrogen gas flow.

The fundamentals of the material transformation and the connected change of the material properties during the nitriding process have been investigated in the last decades [25, 33-35]. The nitriding depth and surface hardness depend on the nitriding time, nitriding temperature and nitrogen concentration which determine the nitrogen diffusion in to the bulk material. The increased hardness of the hot forming steel (black lines) arises primary from the formation of hard nitrides of the alloyed elements like $\mathrm{CrN}$ or TiN within the diffusion zone. In case of higher $\mathrm{N}_{2}$-flows, an additional compound layers can be generated which consists of different kinds of iron nitrides [36]. A compound layer was observable on the steel samples after nitriding with a total gas flow of $80 \%$ in $\mathrm{N}_{2}$. Pre-tests showed nearly no effects on the surface hardness and nitriding depths when increasing the nitrogen flow above $80 \%$. Furthermore, it was observed that a certain amount of hydrogen is needed to stabilize the plasma.

\subsection{Surface structuring of hot work steel}

In order to examine the effect of the coating process on the laser-structured tool steel surface, two different structure periods $(3.0$ and $6.0 \mu \mathrm{m})$ were applied to the flat substrates to investigate the influence on the coating growing structure. The structure depth was chosen depending on the layer system and the associated layer thickness. To guarantee a continues contact of the a-C:H coating in forming applications, the structure depth of the patterns was chosen to be smaller than the coating thickness.

Using the two-beam DLIP setup, hot work steel substrates were treated to examine its processability with ps laser pulses. Representative WLI images as well as surface profiles of the DLIP structures are shown in Fig. 5. It can be observed that the structural shape of the obtained patterns is well defined. The generated structures have a symmetrical geometry and are similar to the sinusoidal waveform which is typical for the line-like DLIP-structures. The average obtained structure depth was $1.40 \mu \mathrm{m}$ and $1.64 \mu \mathrm{m}$ for the $3.0 \mu \mathrm{m}$ and $6.0 \mu \mathrm{m}$ spatial periods, respectively. These depths were achieved using a laser fluence of $0.86 \mathrm{~J} / \mathrm{cm}^{2}$ and a pulse overlap of $97.5 \%$. For overlaps below $95 \%$, the structure depth was smaller than $\sim 1.0 \mu \mathrm{m}$ (not shown).
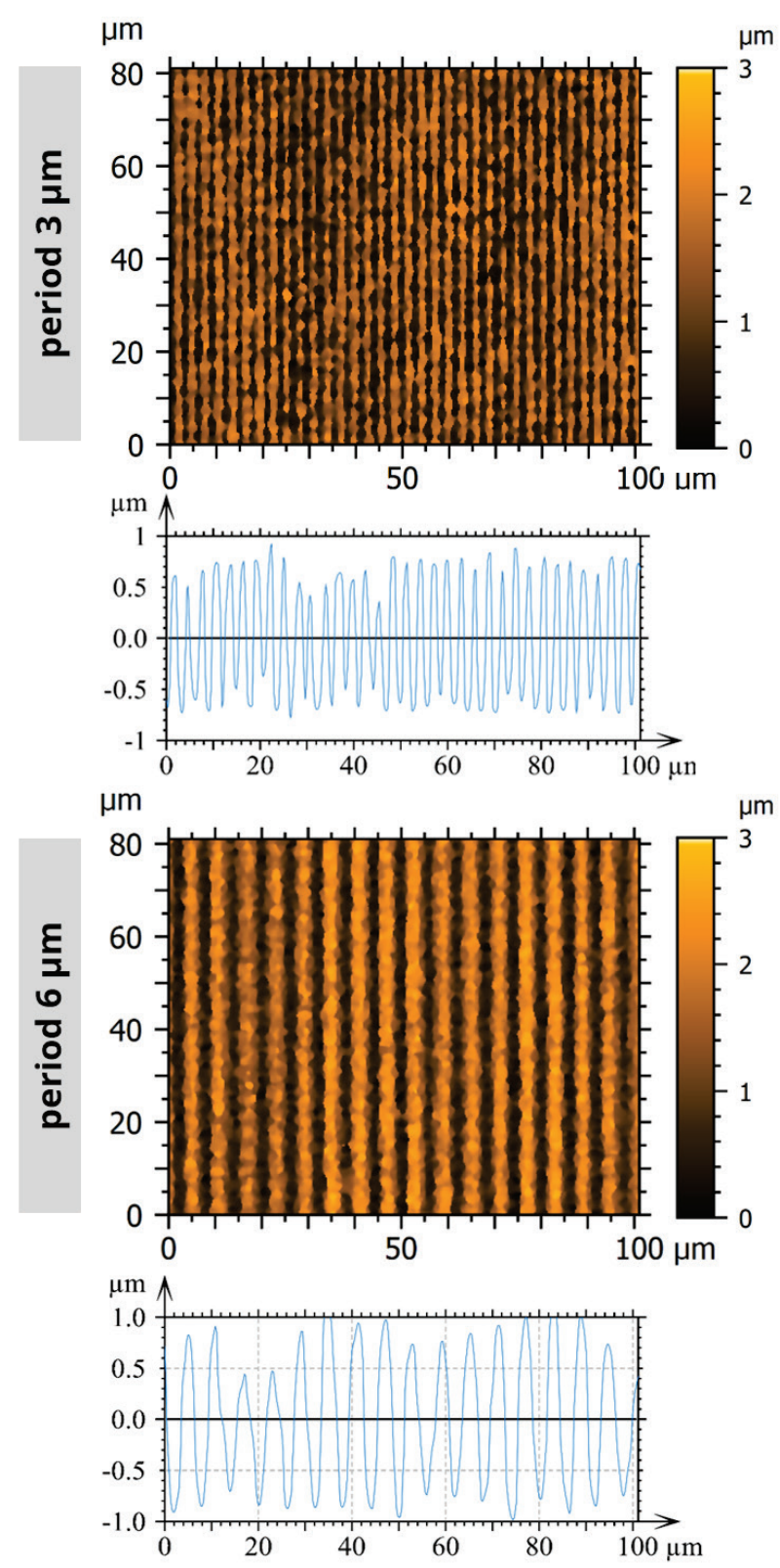

Fig. 5 Topography images and profile sections of DLIP structured uncoated tool steel with $3 \mu \mathrm{m}$ and $6 \mu \mathrm{m}$ spatial periods.

After that, the influence of the nitriding process on the laser processing behavior was investigated. The hot work tool steel was therefore treated with two different nitriding parameters and compared to the standard material. It could not be determined any influence on the structure depth of the different treatment variants. For example, the structure depth of the non-nitrided steel when using $0.87 \mathrm{~J} / \mathrm{cm}^{2}$ and $90 \%$ overlap was $0.56 \mu \mathrm{m}$, while for the nitride samples with $10 \%$ and $80 \%$ of $\mathrm{N}_{2}$ was 0.58 and $0.56 \mu \mathrm{m}$, respectively.

After the quantitative analysis of the surface topography, possible changes of the chemical composition (N, O, Fe) after the DLIP laser treatment was performed using EDX-spectroscopy. For this purpose, three material variants were examined after the laser process and compared with the untreated references. As it can be observed in Fig. 6 , the standard material without treatment process contains a very small amount of nitrogen $(\mathrm{N})$. Clearly, the amount of nitrogen increases as a result of the different nitriding pro- 
cesses. The highest nitrogen content is obtained for the sample nitrided with $80 \%$ of $\mathrm{N}_{2}$ gas flow.

After the laser process, the amount of nitrogen is reduced. In particular, the amount of Oxygen increases due to the heating of the material surface by the laser treatment which since oxygen $(\mathrm{O})$ can diffuse into the material. The amount of oxygen also changed with the laser setting parameters. For the higher pulse overlaps, more oxygen is absorbed at the materials surfaces since more laser pulses are applied. This effect is also responsible for the reduction in the nitrogen content.

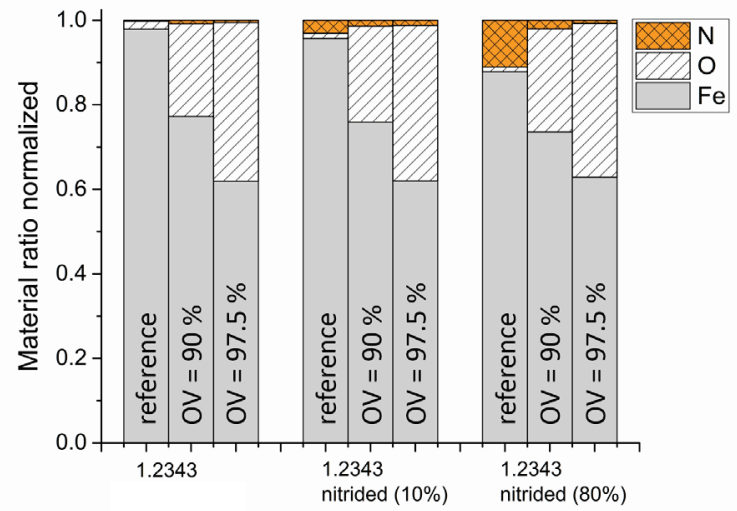

Fig. 6 Chemical distribution of elements before and after the laser process for 3 different evaluated conditions.

\subsection{Combination of structure and coating system}

After the laser structuring process, the steel surfaces were coated with an a-C:H coating system The structured and subsequently coated substrates are shown in Fig. 7.

Based on the surface topography analysis, it can be seen that that, in case of the samples treated with a $3 \mu \mathrm{m}$ structure period, no uniform structure was detectable. This means, that during the deposition process the line-like geometry was covered by the a-C:H coating system. This effect can be explained with an inhomogeneous growing process leading to an increased deposition rate in surface valleys and thus erasing the line geometry [37]. In case of the $6 \mu \mathrm{m}$ period, a lower structure depth was measured compared to the uncoated reference, however, the line shape can be very well recognized. Overall, the structure depth was reduced about $20 \%$ from $1.64 \pm 0.12 \mu \mathrm{m}$ to $1.36 \pm 0.18$ $\mu \mathrm{m}$ after the coating deposition process.

As a critical property for the application in forming processes, the adhesive strength of the a-C:H coating system to the structured steel surface were tested by Rockwell indentation tests, as shown in Fig. 8. According to the tests, the adhesive strength of the coating decreases with a higher structure depth and shorter spatial periods. In general, the coating delaminates from the structured steel surfaces indicating an insufficient adhesive strength for the utilization in forming processes.

Using the plasma nitrided hot work steel, the adhesive strength of the a-C:H coating system to the structured surface was significantly improved (see Fig. 9). In case of a structure depth of $1.7 \mu \mathrm{m}$, no delamination of a-C:H coating system was observed for the $3 \mu \mathrm{m}$ and $6 \mu \mathrm{m}$ line-like structures. Furthermore, there were also no differences between the two nitriding parameter sets. So neither the nitriding depths nor the presence of a compound layer have a signifi- cant influence on the adhesive strength of the a-C:H coating system under these test conditions (room temperature, air). Thus, for the application of DLIP structured and a-C:H coated tools in forming processes, a prior plasma nitriding of the tool steel is necessary. The benefits of using the plasma nitriding process for $\mathrm{Al}$ cold forming was tested at room temperature, permitting to evaluate the adhesive strength of the a-C:H coating to the steel. Preliminary tests at higher temperatures have also shown a significant influence on the performance of nitrided tool steels [37]. However, further tests at higher temperatures are needed to qualify the structured and a-C:H coated tool surface for warm forming processes.
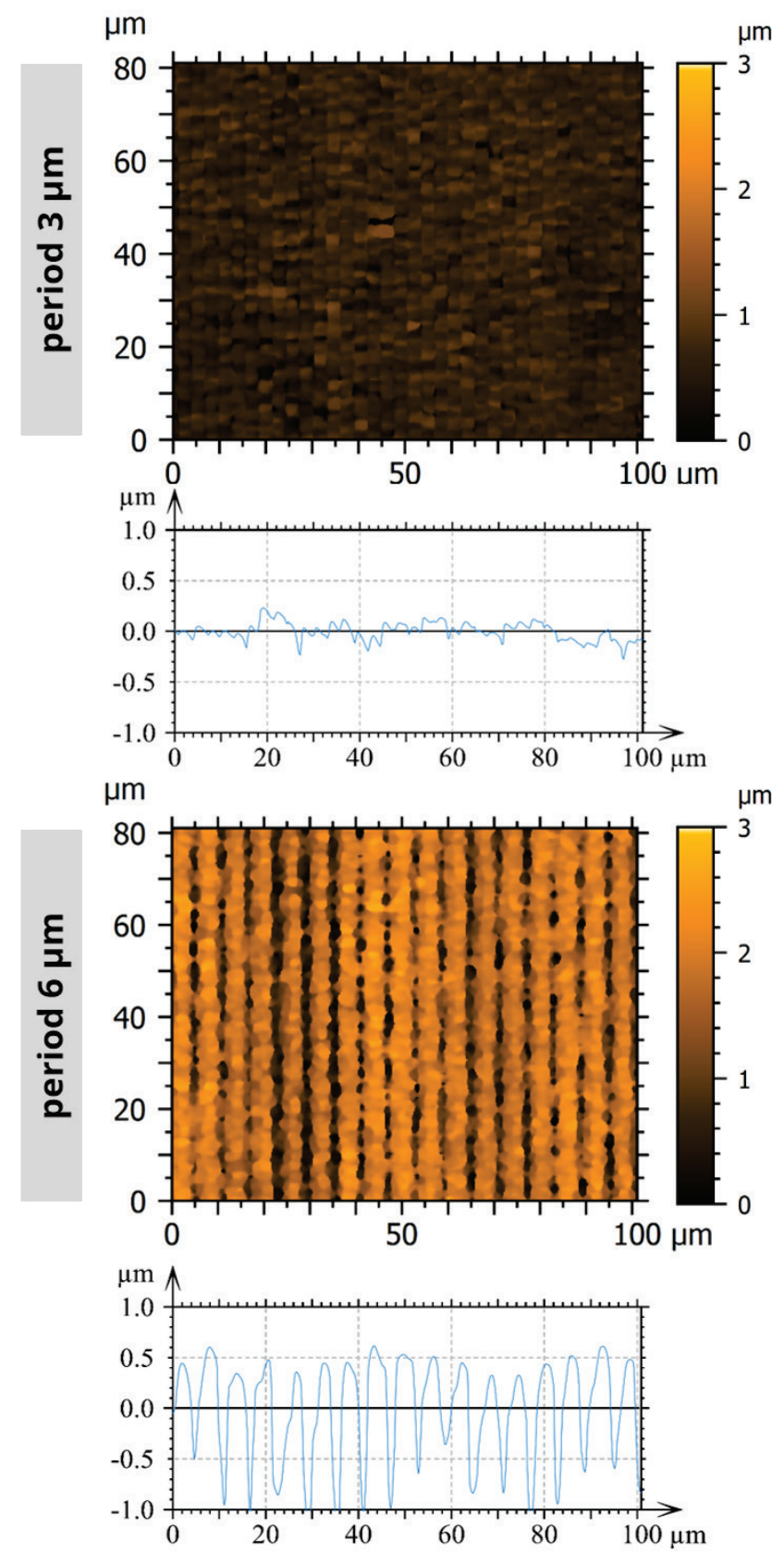

Fig. 7 Topography images and profile sections of DLIP structured and subsequently coated tool steel (1.2343) with a spatial period of $3 \mu \mathrm{m}$ (top) and $6 \mu \mathrm{m}$ (bottom). 


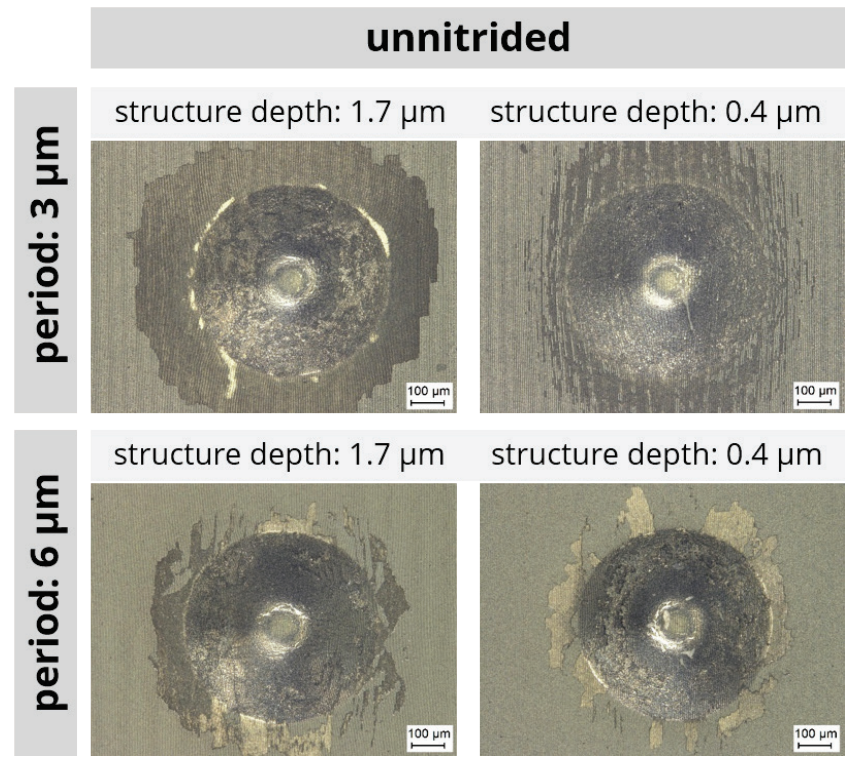

Fig. 8 Adhesive strength of the a-C:H coating system to linear structured hot work steel (1.2343) evaluated by Rockwell indentation tests.

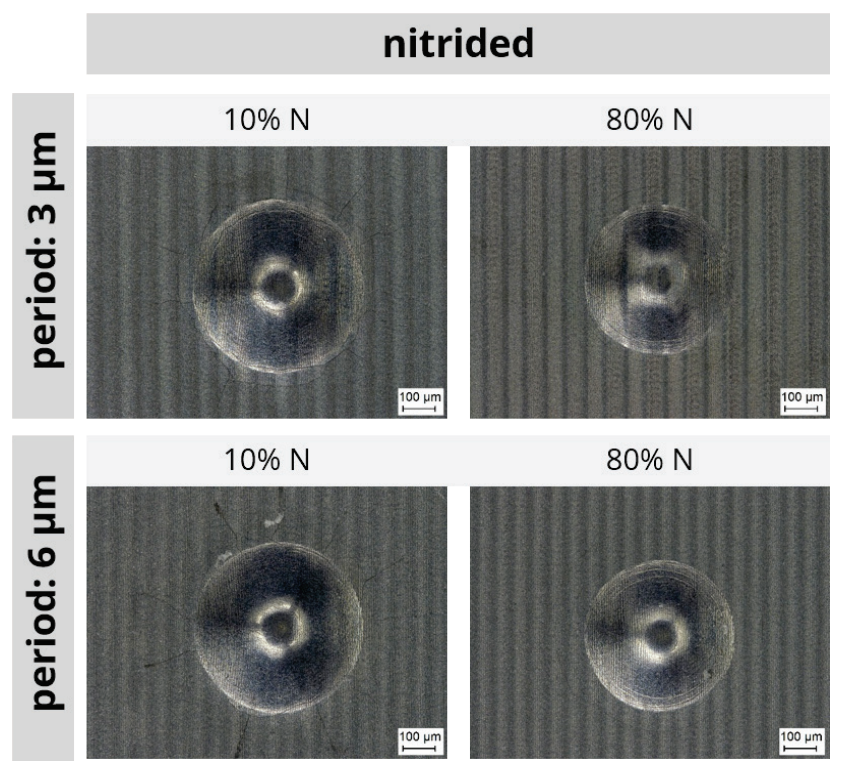

Fig. 9 Adhesive strength of the a-C:H coating system to plasma nitrided and DLIP structured $(1.7 \mu \mathrm{m}$ depth) hot work steel (1.2343) evaluated by Rockwell indentation tests.

\subsection{Tribological test results}

In the tribological study test, specimens with different structuring parameters were examined, using the method which was previously described in 2.3 . Fig. 10 shows the friction coefficient results of the load step test of the selected samples. The line-like structure with $80 \%$ pulse to pulse overlap lies above the reference in all load levels up to $50 \mathrm{MPa}$. Furthermore, the test was stopped at load level $76 \mathrm{MPa}$, by stick and slip conditions. The line-like structure with $95 \%$ overlap have a coefficient of friction advantage over the reference at low load levels up to approx. $16 \mathrm{MPa}$. The load level $30 \mathrm{MPa}$ represents the transition area, in which the reference has better friction values than the DLIP structures. The evaluation of the deviation of the stroke movement per load level confirms the results (not shown).

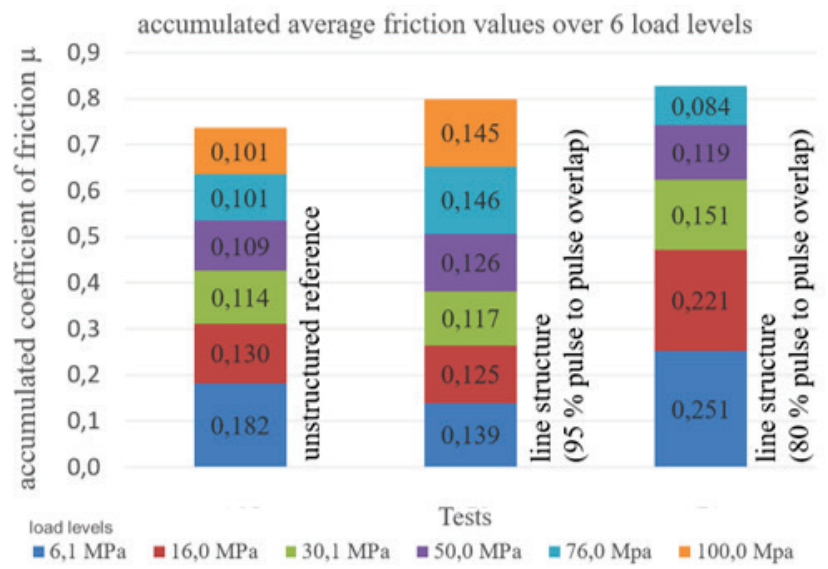

Fig. 10 Tribological test results for the load stage method of DLIP structured specimens and the reference.

\section{Conclusions}

In this work, the DLIP structuring technology was combined with a PVD-PACVD deposition of an a-C:H coating system to modify hot work steel surfaces for the application in aluminum forming processes. The structuring parameter were varied and the resulting adhesive strength of the a-C:H coating system was tested to evaluate the feasible structure-coating combinations and a sufficient load resistance for forming applications. Additionaly, plasma nitriding treatments of the hot work steel were conducted prior to the structuring and coating process to validate the potential for improving the adhesive strength of the a-C:H coating to the structured steel surface. The following conclusions can be made based on the investigation:

(i) DLIP permitted to fabricate line-like patterns with $3 \mu \mathrm{m}$ and $6 \mu \mathrm{m}$ spatial periods, with structure depths up to $1.64 \mu \mathrm{m}$.

(ii) The feasible resolution after the a-C:H coating process is limited by the spatial period, since the coating is not deposited efficiently at the valleys of the DLIP structure.

(iii) The adhesive strength of the applied a-C:H coating system to the structured steel surface was according to Rockwell tests insufficient for the forming processes. Specially, for higher structure depth and smaller periods the coatings tends to delaminate.

(iv) The plasma nitriding of the hot work steel leads to a significant improvement of the adhesive strength qualifying all tested structure-coating combinations for the application in forming processes.

(v) Regarding the tribological performance of the laser treated samples, the structure-coating combination produced with a pulse overlap of $95 \%$ led to a reduction of the friction coefficient compared to the unstructured reference at lower pressures (up to approximately $16 \mathrm{MPa}$ ). This improvement is reflected in a lower cumulative coefficient of friction and a lower wear value. When applying higher loads as well as for samples treated with smaller pulse overlaps $(80 \%)$, the surface properties of the structured samples resulted in a higher friction and wear values. However, considering the significant improvements in the adhesion of deposited coatings due to the DLIP treatment, even surfaces showing similar friction and wear values compared to an untreated surface are huge advantage. Further research is necessary in the future for evaluating the life performance of these surfaces. 
In future works, the structure geometries and tool coatings will be varied to adjust the tribological and hydrodynamic properties. One goal will be the reduction of lubricants needed in forming processes of aluminum. Moreover, the structure will be used to realize tailored tool surfaces with locally optimized tribological properties. By certain coating-structure-systems, the friction value can be adjusted without increasing the adhesion tendency. Applying various coating-structure-systems according to the local load regime on the tool surface gives the opportunity to control the material flow during the forming process which results in higher forming rates and an improved part quality.

\section{Acknowledgments}

This research was funded by the German Federal Ministry of Economics and Energy (BMWi) within the Promotion of Joint Industrial Research Programme (IGF) due to a decision of the German Bundestag. It was part of the research project $19558 \mathrm{BG} / 3$ by the Forschungsgemeinschaft Werkzeuge und Werkstoffe e.V. (FGW) under the auspices of the German Federation of Industrial Research Associations $(\mathrm{AiF})$

\section{References}

[1] P. Groche and F. Resch: Mat.-wiss. u. Werkstofftechn., 46 (2015) 813

[2] C. Daniel, F. Mücklich and Z. Liu: Appl. Surf. Sci., 208-209, (2003) 317.

[3] B. Bhushan and E. K. Her: Langmuir, 26, (2010) 8207.

[4] K. Koch, B. Bhushan, Y. C. Jung and W. Barthlott: Soft Matter, 5, (2009) 1386.

[5] X. Pu, G. Li and H. Huang: Biology Open, 5, (2016) 589.

[6] P. K. Kanaujia and G. V. Prakash: Phys. Chem. Chem. Phys., 18, (2016) 9666.

[7] F. Mücklich and A. Lasagni, C. Int. J. Mat. Res. 97, (2006) 1337.

[8] A.I. Aguilar-Morales, S. Alamri and A.F. Lasagni: J. Mater. Process. Technol., 252, (2018) 313.

[9] A. Rosenkranz, J. C. Pangraz, C. Gachot and F. Mücklich: Wear, 368-369 (2016) 350.

[10]S. Indrisiunas, B. Voisiat, A. Žukauskas and G. Račiukaitis: Proc. SPIE 9350 (2015) 935003.

[11] V. Lang, B. Voisiat and A.F. Lasagni: Materials 12 (2019) 1484.

[12] A.F. Lasagni, T. Roch, J. Berger, T. Kunze and V. Lang: Proc. SPIE 9351 (2015) 935115.

[13] K. Bewilogua and D. Hofmann: Sur. Coat. Technol. 242, (2014) 214.

[14]H. Ronkainen, S. Varjus and K. Holmberg: Wear, 249, (2001) 267.

[15] G. Dumitru, V. Romano, H.P. Weber, S. Pimenov, T. Kononenko, J. Hermann, S. Bruneau, Y. Gerbig and M. Shupegin: Diamond and related Materials, 12, (2003) 1034.

[16] T. Abraham, G. Bräuer, F. Kretz and P. Groche, Dry Met. Forming OAJ FMT 2, (2016) 18.

[17]A. Wank, G. Reisel and B. Wielage, Sur. Coat. Technol. 201, (2006) 822.

[18]H. Ronkainen, S. Varjus and K. Holmberg, Wear 222, (1998) 120.
[19]H. Ronkainen, J. Likonen, J. Koskinen and S. Varjus: Sur. Coat. Technol. 79, (1996) 87.

[20] A. Erdemir, Sur. Coat. Technol. 146-147, (2001) 292.

[21] M. Weber, K. Bewilogua, H. Thomsen and R. Wittorf, Sur. Coat. Technol. 201, (2006) 1576.

[22]F. Cellier and J.F. Nowak, Diamond and Related Materials 3, (1994) 1112.

[23]P. B. Kron, W. Dahl and W. Bleck: Mater. Technol., 68, (1997) 186.

[24]E.H.A. Dekempeneer, L. Poirier, J.P. Lebrun, A. Pasgrimaud, Y. Desalos and F. Balanck: Sur. Coat. Technol. 151-152, (2002), p. 462.

[25] M. Weber, P. Kaestner, K. Koester, H. Thomsen, H. Paschke, Society of Vacuum Coaters, 53rd Annual Technical Conference Proceedings, (2010) p.519.

[26] K. Taube: Sur. Coat. Technol. 98, (1998) 976.

[27] Y. Zabila, M. Perzanowski, A. Dobrowolska, M. Kąc, A. Polit and M. Marszałeka: Acta Physica Polonica A, $115,(2009) 591$.

[28] A.F. Lasagni, T. Roch, D. Langheinrich, M. Bieda and A. Wetzig: Physics Procedia 12, (2011) 214.

[29] J. Marczak, A. Rycyk, A. Sarzyński, M. Strzelec and J. Kusiński: $10^{\text {th }}$ Sympo. Laser Technol., Szczecin (2012) p.8703.

[30] A.I. Aguilar-Morales, S. Alamri, T. Kunze and A.F. Lasagni: Optics and Laser Technol., 107, (2018) 216.

[31] T. Michler and C. Siebert, Sur. Coat. Technol. 163-164, (2003) 546.

[32] W. Rehbein: Annual GfT- Meeting 2014, Göttingen, Germany, Proceedings II, Lecture 13.

[33] K.T. Rie, Sur. Coat. Technol. 112, (1999) 56.

[34] M.U. Devi, T.K. Chakraborty and O.N. Mohanty: Sur. Coat. Technol. 116-119, (1999) 212.

[35] Th. Lampe, S. Eisenberg and E. Rodriguez Cabeo: Sur. Coat. Technol. 174-175, (2003) 1.

[36]H. Paschke, M. Weber, P. Kaestner and G. Braeuer: Sur. Coat. Technol. 205, (2010) 1465.

[37] M.C. Salvadori, D.R. Martins and M. Cattani: Sur. Coat. Technol. 200, (2006) 5119.

(Received: November 11, 2019, Accepted: April 9, 2020) 